\title{
Studies on Water Transport through the Sweet Cherry Fruit Surface: XII. Variation in Cuticle Properties among Cultivars
}

\author{
Stefanie Peschel and Moritz Knoche ${ }^{1}$ \\ Institute for Biological Production Systems, Fruit Science Section, Leibniz University Hannover, \\ Herrenhäuser Straße 2, 30419 Hannover, Germany
}

\begin{abstract}
Additional INDEX words. Prunus avium, cuticular membrane, epidermis, hypodermis, strain, stomata, permeability
Abstract. The cuticular membrane (CM) represents the primary barrier to water uptake into sweet cherry (Prunus avium $\mathbf{L}$.) fruit and thus has a central role in rain-induced cracking. The objective was to quantify $\mathrm{CM}$ properties potentially relevant to cracking and to estimate variance components and broad-sense heritabilities for these traits in selected sweet cherry cultivars. Within the scion cultivars, $C M$ mass per area ranged from $0.85 \mathrm{~g} \cdot \mathrm{m}^{-2}$ in 'Rainier' to $1.61 \mathrm{~g} \cdot \mathrm{m}^{-2}$ in 'Kordia'. Wax mass accounted for one-fourth of $\mathrm{CM}$ mass and ranged from $0.21 \mathrm{~g} \cdot \mathrm{m}^{-2}$ in 'Burlat' to $0.42 \mathrm{~g} \cdot \mathrm{m}^{-2}$ in 'Zeppelin'. Biaxial elastic strain of the $\mathrm{CM}$ averaged $76.7 \%$ across cultivars and ranged from $56.6 \%$ in 'Namosa' to $97.0 \%$ in 'Oktavia'. Strain was a linear function of fruit mass $\left(r^{2}=0.33, P<0.0001\right)$. Partitioning total variance into variance components revealed that fruit mass, $C M$, and wax mass and strain of the $C M$ had a high genotypic variance and a low residual error variance. Stomatal density ranged from $0.12 \mathrm{stomata} / \mathrm{mm}^{2}$ in 'Adriana' to 2.13 stomata $/ \mathrm{mm}^{2}$ in 'Namosa'. The heritability of stomatal density was $67.5 \%$. Across cultivars and years, mean densities of microcracks were of similar orders of magnitude as those of stomata, but ranges were larger and the heritabilities of microcrack density lower. Permeability for transpiration was lowest in 'Flamingo Srim' and highest in 'Nadino'; that for osmotic water uptake was lowest in 'Adriana' and highest in 'Hedelfinger'. Heritability estimates for permeabilities were low. Based on these data, breeding strategies for less cracking susceptible fruit should focus on genotypes that maintain an intact $\mathrm{CM}$ throughout development. This may be achieved by selecting for low $\mathrm{CM}$ strain and high CM thickness because thicker CM have more "reserve" for thinning. Finally, genotypes that deposit cutin and wax also during Stage III would be most interesting but were not found among the cultivars investigated.
\end{abstract}

Rain-induced cracking is an important limitation in sweet cherry production worldwide (Christensen, 1996). Cracking susceptibility differs among cultivars. Cracking is thought to be related to water uptake into the fruit, but the mechanistic basis for differential cracking susceptibility is not entirely clear. Theoretically, the following two groups of factors may account for variation in cracking susceptibility among cultivars: 1 ) the water transport characteristics of the fruit surface; and/or 2) the mechanical constitution of the load-bearing peripheral structure, presumably the exocarp. Both groups of factors are mechanistically unrelated.

The cuticular membrane plays an important role in cracking, because it represents the primary barrier to water transport (Martin and Juniper, 1970). Microscopic cracks in the CM impair this barrier function and allow for uncontrolled and rapid water transport (Knoche and Peschel, 2006). These microcracks occur at high density in sweet cherry grown without rain shelters, because the CM of sweet cherry fruit is markedly strained and thinned in the course of development (Knoche et al., 2004; Peschel and Knoche, 2005) and liquid water on or high concentrations of water vapor above the strained $\mathrm{CM}$ induce microcracks (Knoche and Peschel, 2006). In contrast to water transport, a role of the $\mathrm{CM}$ in the fruit skin integrity is less

Received for publication 22 June 2012. Accepted for publication 7 Aug. 2012. This research was funded in part by a grant from the Deutsche Forschungsgemeinschaft.

We thank Werner Pfannenstiel and Erik Schulte from the federal fruit cultivar office in Marquardt for making their orchards available to us; Matthias Hinz and Evelyn and Ruth Richter for technical assistance; and Thomas Debener and Stan Hokanson for helpful comments on the manuscript.

${ }^{1}$ Corresponding author. E-mail: moritz.knoche@obst.uni-hannover.de. likely because the support of the $\mathrm{CM}$ by underlying epidermal cells is essential for the integrity of the CM (Knoche and Peschel, 2006) and abrading the CM using carborund powder had no effect on the (calculated) fruit turgor (Knoche et al., 2004). If the CM formed a structural shell that held the mesocarp under compression (Considine and Brown, 1981), the fruit turgor should decrease on abrasion of the CM. However, this was not the case. These arguments do not exclude the possibility that microcracks act as stress concentrators and extend into macroscopic cracks during cracking (Glenn and Poovaiah, 1989).

Low cracking susceptibility is an important objective in sweet cherry breeding programs around the world. Improving cracking resistance by breeding approaches requires phenotyping of cracking relevant traits, quantifying their variance components and estimating the broad-sense heritabilities. To our knowledge, such information is not available for sweet cherry.

The objectives of our study were to phenotype crackingrelevant traits in selected sweet cherry cultivars and to quantify their heritability. We focused on CM characteristics such as the $\mathrm{CM}$ and wax mass, the (elastic) strain of the $\mathrm{CM}$, the densities of stomata and of microcracks in the exocarp, and the permeability of the exocarp to water transport in transpiration and in osmotic water uptake.

\section{Materials and Methods}

\section{Plant material}

Sweet cherry fruit of the cultivars Alma, Bianca, Bing, Burlat, Early Rivers, F12/1, Flamingo Srim, Hedelfinger, Hudson, Katalin, Kordia, Margit, Nadino, Namare, Namosa, 
Oktavia, Rainier, Rebekka, Regina, Ria, Rube, Sam, Silvia, Stella, Summit, Sunburst, Techlovan, Van, Vernon, Viola, and Zeppelin were hand-picked from experimental orchards of the federal fruit cultivar office in Marquardt, Germany (lat. 52 $28^{\prime}$ $\mathrm{N}$, long. $12^{\circ} 58^{\prime} \mathrm{E}$ ). The cultivar Adriana was sampled from an experimental orchard at the Horticultural Research Center LVG, Erfurt, Germany (lat. $50^{\circ} 58^{\prime} \mathrm{N}$, long. $11^{\circ} 01^{\prime} \mathrm{E}$ ). All cultivars were grafted on $P$. avium 'Alkavo' rootstocks. Fruit was sampled randomly from three trees per cultivar and mean fruit mass was determined on a minimum of 15 fruit per cultivar and season.

CM mass, wax mass, and strain were quantified in 'Adriana', 'Bianca', 'Burlat', 'Early Rivers', 'F12/1', 'Flamingo Srim', 'Hedelfinger', 'Hudson', 'Katalin', 'Kordia', 'Margit', 'Nadino', 'Namare', 'Namosa', 'Oktavia', 'Rebekka', 'Regina', 'Sam', 'Sunburst', and 'Van' in 1999, 2000, 2001, 2003, and 2004 (only CM mass) at the mature Stage III.

In 2003, CM and wax deposition were quantified in Stage II and mature Stage III 'Adriana', 'Alma', 'Bianca', 'Bing', 'Burlat', 'Early Rivers', 'F12/1', 'Flamingo Srim', 'Hedelfinger', 'Hudson', 'Katalin', 'Kordia', 'Margit', 'Nadino', 'Namare', 'Namosa', 'Oktavia', 'Rainier', 'Rebekka', 'Regina', 'Ria', 'Rube', 'Sam', 'Silvia', 'Stella', 'Summit', 'Sunburst', 'Techlovan', 'Van', 'Vernon', 'Viola', and 'Zeppelin.' Mean fruit mass averaged $1.9 \pm 0.1 \mathrm{~g}$ /fruit (range, 0.6 to $3.9 \mathrm{~g}$ ) during Stage II and $8.3 \pm 0.4 \mathrm{~g}$ /fruit (range, 1.4 to $12.0 \mathrm{~g}$ ) during Stage III.

The permeabilities for transpiration and water uptake were determined in 'Adriana', 'Bianca', 'Burlat', 'Early Rivers', 'F12/1', 'Flamingo Srim', 'Hedelfinger', 'Hudson', 'Katalin', 'Kordia', 'Margit', 'Nadino', 'Namare', 'Namosa', 'Oktavia', 'Rebekka', 'Regina', 'Sam', 'Sunburst', and 'Van' in 1999, 2000, 2001, 2003, and 2004 ( $P_{t}$, all years; $P_{f}, 2003$ and 2004 only) at the mature Stage III. The densities of stomata (all years) and microcracks $(2000,2001,2003,2004)$ were quantified. In 1999, only a simplified two-score rating scheme (with vs. without microcracks) was used.

\section{Procedures}

Mass of Cuticular membrane and wax. Cuticles were isolated enzymatically using standard procedures (Knoche et al., 2004; Orgell, 1955). Exocarp segments (ES) were excised from the median position of the cheek using a cork borer (8.9 or $15.3 \mathrm{~mm}$ diameter). Adhering parenchyma tissue was removed using a razor blade. This ES comprised the CM, epidermis, hypodermis, and some mesocarp tissue. The ES were incubated in a solution containing technical grade pectinase (90 $\mathrm{mL} \cdot \mathrm{L}^{-1}$ Panzym Extra; Novozymes, Bagdsvaerd, Denmark), cellulase $\left(5 \mathrm{~mL} \cdot \mathrm{L}^{-1}\right.$, Celluclast; Novozymes $)$, and $50 \mathrm{~mm}$ citric acid buffer at $\mathrm{pH}$ 4.0. Sodium azide was added at a final concentration of $30 \mathrm{~mm}$ to suppress microbial growth. The enzyme solution was refreshed periodically until CMs separated from adhering tissue. When appropriate, the cleaning was supported by carefully removing cellular debris from the $\mathrm{CM}$ using a fine camel hair brush. Isolated CMs were rinsed 10 times in deionized water, dried at $40{ }^{\circ} \mathrm{C}$, and weighed. Except for 2004, wax was extracted by incubating isolated $\mathrm{CMs}$ in chloroform/methanol $(1: 1, \mathrm{v} / \mathrm{v})$ at $38^{\circ} \mathrm{C}$ for $30 \mathrm{~min}$. The extraction procedure was repeated 10 times. The extracted dewaxed CM were re-dried and re-weighed and the amount of wax calculated as the mass loss during extraction. Mass of CM and wax per unit fruit surface area was calculated by dividing $\mathrm{CM}$ and wax mass per disc by the area that the $\mathrm{CM}$ originally covered on the fruit surface. The minimum number of replications was four with 10 to 15 discs per replicate and one disc per fruit.

Strain of The CUTICUlar Membrane. The biaxial elastic strain of the ES was quantified as described previously (Knoche and Peschel, 2006). Fully hydrated CM discs were spread on a microscope slide in a drop of water and photographed at $\times 4$ (MZ6 microscope; Leica Mikrosysteme, Bensheim, Germany) using a video camera (HV-C20 E/K-S4; Hitachi Denshi Europa, Rodgau, Germany). The area of the CM disc was quantified by image analysis (analySIS 3.0 software package; Soft Imaging System, Münster, Germany) (Knoche et al., 2004). The biaxial elastic strain [ $\varepsilon$ (percent)] was calculated according to Eq. [1], where $A$ represents the surface area of the CM covered on the fruit before excision and $A_{O}$ the area of the relaxed CM following isolation:

$$
\varepsilon=\frac{A-A_{O}}{A_{O}} \cdot 100
$$

The $A$ was calculated as the surface area of a cap of a sphere having a diameter equivalent to the cork borer and assuming a spherical shape of the fruit as a first approximation. The minimum number of replications was five.

Permeability IN TRANSPIRATION AND IN OSMOTIC WATER UPTAKE. Permeabilities of ES in transpiration $\left(\mathrm{P}_{t}\right)$ and water uptake $\left(\mathrm{P}_{\mathrm{f}}\right)$ were determined as described previously (Beyer and Knoche, 2002; Knoche et al., 2000). Briefly, ES ( $\approx 12 \mathrm{~mm}$ diameter) were excised from the cheek of the fruit using a razor blade. The cut edge was blotted on tissue paper to remove surface moisture. Subsequently, ES were mounted in stainless steel diffusion cells (see Fig. 1A in Knoche et al., 2000) using high-vacuum grease (Hochvakuumfett schwer; WackerChemie, München, Germany). The area of the orifice of the diffusion cell $\left(A_{\text {segment }}\right)$ was $38.5 \mathrm{~mm}^{2}$. Diffusion cells were turned upside down and $0.5 \mathrm{~mL}$ of deionized water was pipetted into the cell through a hole in the bottom. Subsequently, the cell was sealed with tape (tesa ${ }^{\circledR}$ Film; tesa-Werke Offenburg, Offenburg, Germany). Diffusion cells were positioned in a closed polyethylene box above dry silica such that the distance between the silica and the exocarp surface was not larger than $2 \mathrm{~mm}$. This setup prevented the formation of a stagnant air layer above the cuticle and hence boundary layer resistance was negligible (Knoche et al., 2000). The amount of water transpired through the exocarp was determined gravimetrically by repeated weighing of diffusion cells (four or five times) at regular time intervals ( 1 to $2 \mathrm{~h}$ ).

In 2003 and 2004, water uptake assays were conducted on the same ES used to quantify the permeability in transpiration the day before. Overnight, the orifice of the diffusion cells was sealed with tape to minimize transpiration. In the mornings, the water donor from the transpiration assay was replaced by the receiver solution of the water uptake assay. This receiver solution contained polyethylene glycol (PEG-6000; Merck Eurolab, Darmstadt, Germany) at $1140 \mathrm{mmol} \cdot \mathrm{kg}^{-1}$ (Beyer and Knoche, 2002). This osmolality corresponded to a typical osmolality of sweet cherry sap extracted from mature fruit (Beyer and Knoche, 2002). Subsequently, the hole in the bottom of the diffusion cells was re-sealed with tape (tesa ${ }^{\circledR}$ Film). Water uptake experiments were initiated by applying 0.10 to $0.15 \mathrm{~mL}$ of deionized water to the orifice of the diffusion cell such that the entire area of the exposed ES $\left(38.5 \mathrm{~mm}^{2}\right)$ was 
Table 1. Mass of fruit, cuticular membrane (CM), and wax, and strain of the CM of selected sweet cherry cultivars.

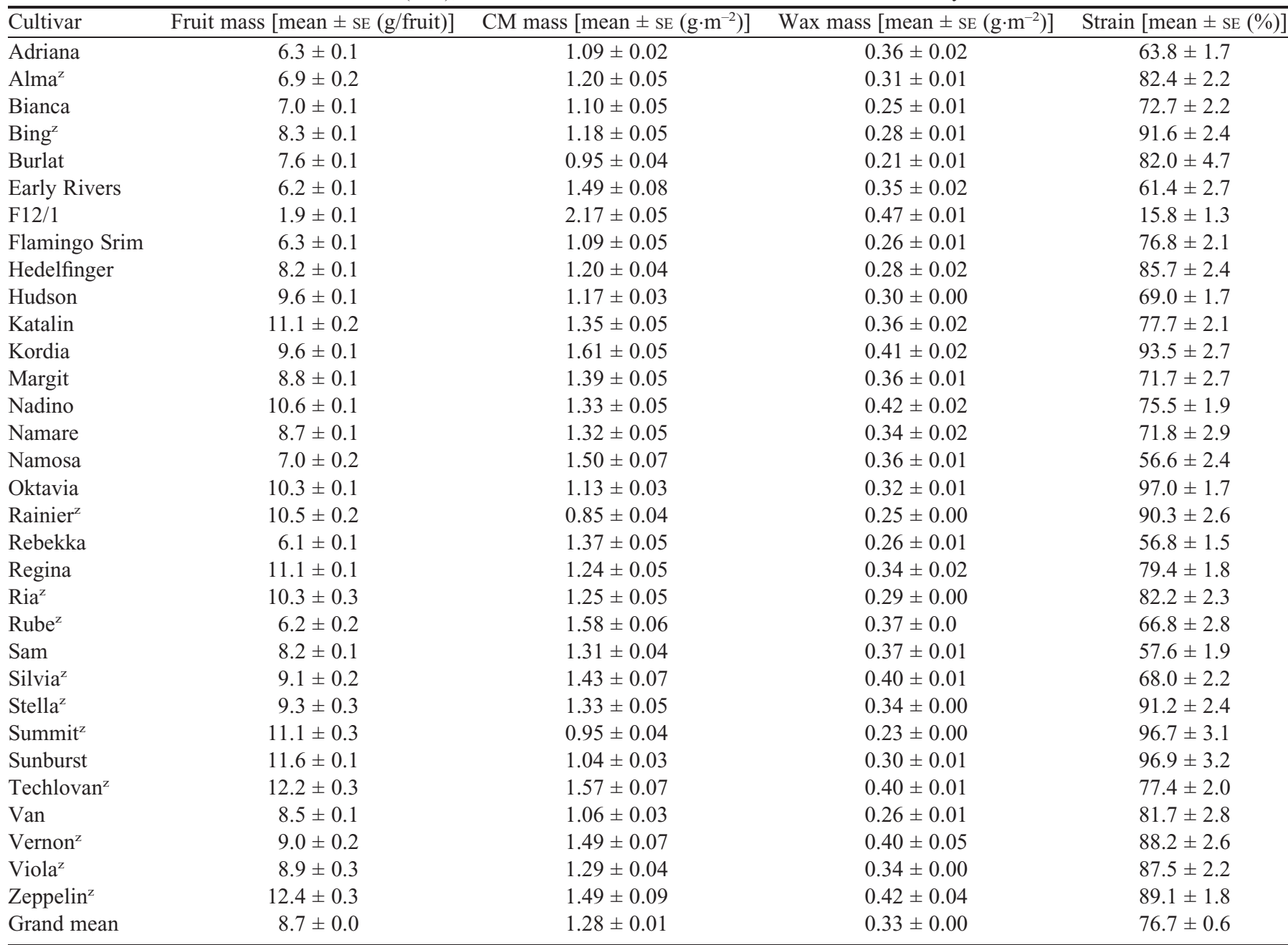

${ }^{\mathrm{z} C u l t i v a r s ~ s t u d i e d ~ i n ~} 2003$ only; all other cultivars in 1999, 2000, 2001, 2003, and 2004 (except for wax).

covered. Diffusion cells were incubated in an upright position at $25{ }^{\circ} \mathrm{C}$ (see Beyer and Knoche, 2002). Water uptake was monitored gravimetrically. The donor was removed quantitatively at $0,1,2,4$, and $6 \mathrm{~h}$ by blotting with soft tissue paper. Thereafter, the diffusion cell was weighed to determine water uptake and the donor solution reapplied. After water transport experiments, the number of stomata and of short microcracks (i.e., shorter than the underlying epidermal cell) and long microcracks (i.e., longer than the underlying epidermal cell) were established on an individual ES basis by fluorescence light microscopy at $\times 100$ (Model BX-60; Olympus Optical Co., Europa, Hamburg, Germany). The microcracks were infiltrated with acridine orange $(0.1 \% \mathrm{w} / \mathrm{v})$ for $2 \mathrm{~min}$ (Peschel et al., 2003; Peschel and Knoche, 2005). Densities of stomata $\left(d_{s t o}\right)$ and of short $\left(d_{\text {short cracks }}\right)$ and long microcracks $\left(d_{\text {long cracks }}\right)$ were calculated by dividing the number of stomata or micocracks per ES by the area of the ES exposed in the diffusion cell $\left(38.5 \mathrm{~mm}^{2}\right)$.

\section{Terminology, data analysis, and presentation}

The permeabilities $\left[\mathrm{P}\left(\mathrm{m} \cdot \mathrm{s}^{-1}\right)\right]$ in transpiration $\left(\mathrm{P}_{\mathrm{t}}\right)$ and in osmotic water uptake $\left(\mathrm{P}_{\mathrm{f}}\right)$ were calculated from the rate of water transport $\left[F\left(\mathrm{~kg} \cdot \mathrm{s}^{-1}\right)\right]$ in transpiration $\left(F_{t}\right)$ and in water uptake $\left(F_{f}\right)$, the density of water $\left[\rho_{w}\left(\mathrm{~kg} \cdot \mathrm{m}^{-3}\right)\right]$, the area of the ES exposed in the diffusion cell $\left(A=38.5 \times 10^{-6} \mathrm{~m}^{2}\right)$, and the respective driving forces $\left[\Delta a_{w}\right.$ (dimensionless)] for transpiration and water uptake according to Eq. [2] (Beyer and Knoche, 2002; Beyer et al., 2005).

$$
\mathrm{P}=\frac{F}{A \cdot \rho_{w} \cdot \Delta a_{w}}
$$

In transpiration, $\Delta a_{w}$ equaled the gradient in water vapor activity between the inside of the diffusion cell $\left(a_{w}^{\text {inside }}=1\right)$ and the ambient atmosphere outside of the diffusion cell $\left[a_{w}^{\text {outside }}=0\right.$ (for details see Beyer et al., 2005)]. In osmotic water uptake, the $\Delta a_{w}$ was calculated using Eq. [3] where $\Delta \Psi$ represented the gradient in water potential $(\Delta \Psi)$ between the water donor solution on the surface of the ES and the PEG receiver solution inside the diffusion cell and $\frac{V_{w}}{R T}[137.3 \mathrm{MPa}$ at $25^{\circ} \mathrm{C}$ (Nobel, 1999)] the molar volume of water $V_{w}$ divided by the product of the universal gas constant $(R)$ and the absolute temperature [ $T$ (for details see Beyer et al., 2005)].

$$
\Delta a_{w}=\frac{\Delta \Psi \overline{V_{w}}}{R T}
$$

Rates of transpiration $\left(F_{t}\right)$ and of osmotic water uptake $\left(F_{f}\right)$ were determined on an individual ES basis by fitting a linear 
regression line through a plot of cumulative transpiration or water uptake vs. time. The slope of this regression line represented the respective $F_{t}$ and $F_{f}$. Only observations on diffusion cells having an $r^{2}>0.50$ were used (transpiration mean $\mathrm{r}^{2}=$ $0.992, \mathrm{n}=2009$; uptake mean $\left.r^{2}=0.927, \mathrm{n}=564\right)$. The observations remaining $(\mathrm{n}=14$ to 25 per cultivar and year) represented $99.0 \%$ and $96.6 \%$ of the total population of ES for transpiration and water uptake, respectively.

Components of variance were estimated using Proc Mixed with the option method = REML (SAS Version 9.1.3; SAS Institute, Cary, NC). The broad sense heritability $(H)$ was calculated according to Eq. [4]:

$$
H=\frac{\sigma_{G}^{2}}{\sigma_{Y}^{2}+\sigma_{Y x G}^{2}+\sigma_{R}^{2}}
$$

In this equation, $\sigma_{G}^{2}$ represented the variance component for the variance among genotypes, $\sigma_{Y}^{2}$ the variance component for the variance among years, $\sigma_{Y x G}^{2}$ the variance component for the variance associated with the interaction genotype $\times$ year, and $\sigma_{R}^{2}$ the variance component for the residual variance that resulted from fruit-to-fruit variation and any variability associated with our experimental techniques. This procedure uses the variance associated with years as an estimate for the environmental variance component. To obtain normal distributions, densities of microcracks, and the permeabilities for transpiration and for osmotic water uptake were log-transformed. Linear regression and multiple stepwise regression analyses were carried out using Proc Reg and Proc Stepwise (SAS Version 9.1.3). Data are presented as means and SES. Where error bars are not shown, they were smaller than data symbols.

\section{Results}

\section{Mass of cuticular membrane and wax and strain}

Among the scion cultivars, CM mass per area and hence thickness ranged from $0.85 \mathrm{~g} \cdot \mathrm{m}^{-2}$ in 'Rainier' to $1.61 \mathrm{~g} \cdot \mathrm{m}^{-2}$ in 'Kordia' (Table 1). Only the very small fruit from the ' $F 12 / 1$ ' rootstock had a higher CM mass per unit surface area $\left[2.17 \mathrm{~g} \cdot \mathrm{m}^{-2}\right.$ (Table 1)]. On a whole fruit basis, 'Burlat' had the lowest CM mass per fruit [1.68 mg/fruit (data not shown)] and 'Kordia' the highest (3.54 mg/fruit). Across cultivars, CM mass per fruit was positively related to fruit mass $\left[r^{2}=0.34 ; P<0.0001\right.$ (data not shown)], whereas CM mass per unit area was unaffected (without 'F12/1' fruit) or negatively related to fruit mass [with 'F12/1' fruit, $r^{2}=0.08, P=0.0004$ (Fig. 1A)].

On average wax mass accounted for one-fourth of CM mass and ranged from $0.21 \mathrm{~g} \cdot \mathrm{m}^{-2}$ in 'Burlat' to $0.42 \mathrm{~g} \cdot \mathrm{m}^{-2}$ in 'Zeppelin' (Table 1). Fruit from the rootstock ' $\mathrm{F} 12 / 1$ ' had an even higher wax mass per unit area $\left(0.47 \mathrm{~g} \cdot \mathrm{m}^{-2}\right)$. Across cultivars, wax mass per unit area was positively and linearly related to $\mathrm{CM}$ mass per unit area $\left[r^{2}=0.64, P<0.0001\right.$ (Fig. 1B)].

On excision of the ES and isolation of the CM, the surface area of the CM decreased indicating the presence of significant elastic strain in the CMs of all cultivars. Across cultivars, strain averaged $76.7 \%$ and ranged from $56.6 \%$ in 'Namosa' to $97.0 \%$ in 'Kordia' (Table 1). Only the CM of the small fruit of the ' $F 12 / 1$ ' rootstock was less strained $[15.8 \%$ (Table 1)]. Across cultivars strain was a linear function of fruit mass $\left[r^{2}=0.33, P<0.0001\right.$ (Fig. 1C)]. Generally, thinner CMs were more strained $\left[r^{2}=0.34, P<0.0001\right.$ (Fig. 1D)]. Multiple
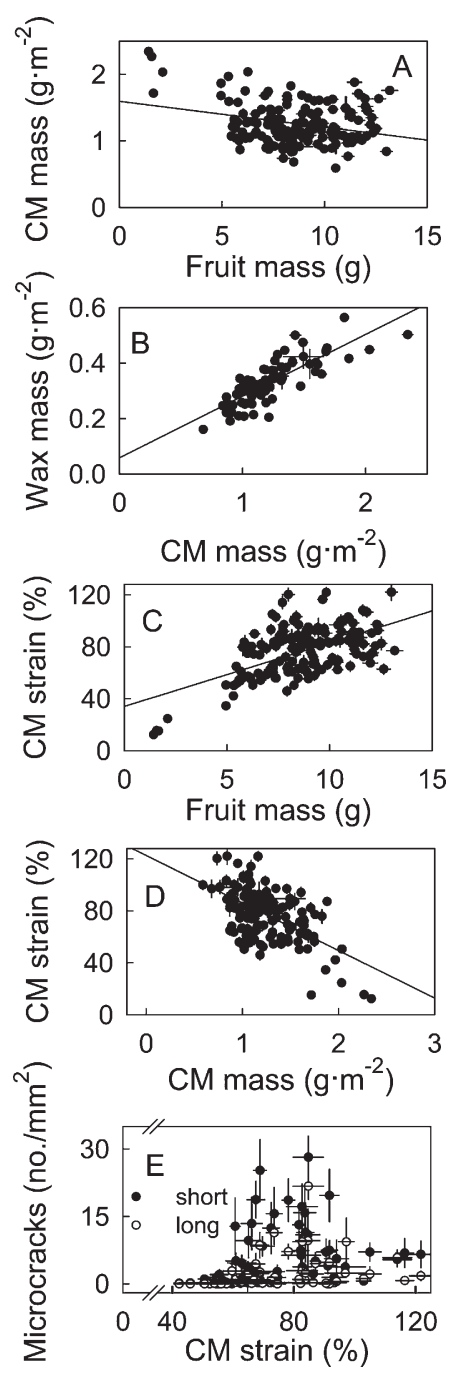

Fig. 1. Relationship between the mass of cuticular membrane (CM) and fruit mass (A), between CM mass and wax mass (B), between fruit mass and strain of the CM (C), and between CM mass and strain (D) and the density of short and long microcracks and strain of the CM (E). Strain was calculated as the relative decrease in area of the $\mathrm{CM}$ disc after excision from the fruit using a cork borer and enzymatic isolation. The number of short microcracks (i.e., shorter than the underlying epidermal cell) and long microcracks (i.e., longer than the underlying epidermal cell) was established on excised exocarp segments from the cheek of mature sweet cherry fruit. Data symbols represent means \pm SE for a single cultivar in one year.

linear regression analysis revealed that $66 \%$ of the strain of the $\mathrm{CM}$ at maturity $\left(r^{2}=0.66, P<0.0001\right)$ was accounted for by fruit surface area (partial $r^{2}=0.51, P<0.0001$ ) and CM mass per unit surface area (partial $\left.r^{2}=0.15, P<0.0016\right)$. There was no improvement of the model $\left(r^{2}=0.65, P<0.0001\right)$ when strain was related to the increase in surface area between Stages II and III (partial $r^{2}=0.54, P<0.0001$ ) or to the amount of cuticle deposited between Stages II and III (partial $r^{2}=0.11$, $P=0.0059)$.

Partitioning total variance into variance components caused by the factors genotype, year, the interaction genotype $\times$ year, and a remaining residual error revealed that for fruit mass, CM mass, wax mass, and strain of the CM the largest variance component was always associated with the genotype (Table 2). For these traits, estimates of the broad-sense heritability were $40.6 \%$ or greater (Table 2 ). 
Table 2. Variance components and broad-sense heritability of selected traits of sweet cherry. ${ }^{\mathrm{z}}$

\begin{tabular}{|c|c|c|c|c|c|}
\hline \multirow[b]{2}{*}{ Trait } & \multicolumn{4}{|c|}{ Variance component (estimate $\pm \mathrm{SE}$ ) } & \multirow[b]{2}{*}{ Heritability estimate $(\%)$} \\
\hline & Genotype & Year & Genotype $\times$ year & Residual & \\
\hline Fruit mass (g/fruit) & $4.44 \pm 1.53$ & $0.11 \pm 0.12$ & $0.81 \pm 0.15$ & $1.00 \pm 0.03$ & 69.8 \\
\hline $\mathrm{CM}$ mass $\left(\mathrm{g} \cdot \mathrm{m}^{-2}\right)$ & $0.058 \pm 0.020$ & $0.045 \pm 0.032$ & $0.017 \pm 0.030$ & $0.002 \pm 0.000$ & 47.6 \\
\hline Wax mass $\left(\mathrm{g} \cdot \mathrm{m}^{-2}\right)$ & $0.0031 \pm 0.0010$ & $0.0028 \pm 0.0023$ & $0.0012 \pm 0.0002$ & $0.0003 \pm 0.0000$ & 42.6 \\
\hline Wax mass (g/fruit) & $0.030 \pm 0.010$ & $0.009 \pm 0.007$ & $0.004 \pm 0.001$ & $0.001 \pm 0.000$ & 69.1 \\
\hline Strain $(\%)$ & $213.6 \pm 87.5$ & $38.3 \pm 35.4$ & $185.9 \pm 35.0$ & $88.0 \pm 4.9$ & 40.6 \\
\hline$d_{\text {crack short }}\left(\right.$ microcracks $\left./ \mathrm{mm}^{2}\right)$ & $3.4 \pm 1.5$ & $0.0 \pm 0.0$ & $2.1 \pm 0.7$ & $26.3 \pm 1.0$ & 10.8 \\
\hline$d_{\text {crack long }}\left(\right.$ microcracks $\left./ \mathrm{mm}^{2}\right)$ & $0.64 \pm 0.32$ & $0.27 \pm 0.29$ & $0.76 \pm 0.24$ & $8.67 \pm 0.32$ & 6.2 \\
\hline $\log P_{t}\left(m \cdot s^{-1}\right)$ & $0.007 \pm 0.003$ & $0.027 \pm 0.020$ & $0.015 \pm 0.003$ & $0.019 \pm 0.001$ & 9.7 \\
\hline $\log \mathrm{P}_{\mathrm{f}}\left(\mathrm{m} \cdot \mathrm{s}^{-1}\right)$ & $0.068 \pm 0.030$ & $0.037 \pm 0.055$ & $0.017 \pm 0.008$ & $0.103 \pm 0.006$ & 30.3 \\
\hline
\end{tabular}

zThe traits investigated were fruit mass, mass of the cuticular membrane (CM) per area or per fruit, mass of wax per area or per fruit, strain of the CM, the densities of stomata $\left(d_{\text {sto }}\right)$ of small $\left(d_{\text {short crack }}\right)$ and large microracks $\left(d_{\text {long crack }}\right)$ and the permeabilities of the exocarp in transpiration $\left(\mathrm{P}_{\mathrm{t}}\right)$ and in osmotic water uptake $\left(\mathrm{P}_{\mathrm{f}}\right)$. Permeability data were log transformed to establish normal distributions. Strain was calculated as the relative decrease in area of the CM disc after excision from the fruit using a cork borer and enzymatic isolation. For details, see text.

Across all cultivars investigated, the CM and wax mass during Stage II were positively and linearly related to CM and wax mass at the mature Stage III, respectively, both on an area and a whole fruit basis (Fig. 2; Table 3). For CM and wax mass on a whole fruit basis, the slope terms were close to 1 indicating that little deposition of CM and wax occurred between Stage II and the mature Stage III.

\section{Density of stomata, microcracks, and permeabilities for water transport}

The density of stomata on the cheek of the scion cultivars ranged from 0.12 stomata $/ \mathrm{mm}^{2}$ in 'Adriana' to 2.13 stomata $/ \mathrm{mm}^{2}$ in 'Namosa' that was only exceeded by the rootstock 'F12/1' [3.59 stomata $/ \mathrm{mm}^{2}$ (Table 4)]. The heritability of stomatal density was high $[67.5 \%$ (Table 2$)]$.

Across cultivars and years, mean densities of short $(2.31$ microcracks $\left./ \mathrm{mm}^{2}\right)$ and long microcracks (0.79 microcracks/ $\mathrm{mm}^{2}$ ) were of similar orders of magnitude as those of stomata (1.10 stomata $/ \mathrm{mm}^{2}$ ), but ranges were markedly larger (from 0.18 to 7.09 and 0.02 to $4.23 \mathrm{microcracks} / \mathrm{mm}^{2}$ for short and long microcracks, respectively). Also, the heritabilities of microcrack density were markedly lower than that for stomatal density (Table 2). Furthermore, the large variance component associated with the residual variability of microcrack densities indicated significant fruit-to-fruit variation within cultivars and years (Table 2).

Permeability for transpiration was lowest in 'Flamingo Srim' and highest in 'Nadino' and that for osmotic water uptake lowest in 'Adriana' and highest in 'Hedelfinger' (Table 4). Estimating variance components revealed that the variance components for the residual error exceeded those caused by the cultivars. Also, heritability estimates were low, more so for $\mathrm{P}_{\mathrm{t}}$ than for $\mathrm{P}_{\mathrm{f}}$ (Table 2). Multiple linear regression analysis revealed that the density of long microcracks accounted for $16 \%$ and $45 \%$ of the variability in $\mathrm{P}_{t}$ and $\mathrm{P}_{\mathrm{f}}$, respectively (Table 5; Fig. 3A-B). CM mass per unit area (partial $r^{2}=0.069$, $P=0.0227)$ further increased the variability in $\mathrm{P}_{\mathrm{t}}$ accounted for to $23.3 \%(P=0.0003)$. For $\mathrm{P}_{\mathrm{f}}$, introducing stomatal density (partial $r^{2}=0.080, P=0.0456$ ) and the strain of the $\mathrm{CM}$ (partial $r^{2}=0.045, P=0.1174$ ) increased the $r^{2}$ to $57.2 \%$ of the variability accounted for $[P<0.0001$ (Table 5) $] . \mathrm{P}_{\mathrm{t}}$ and
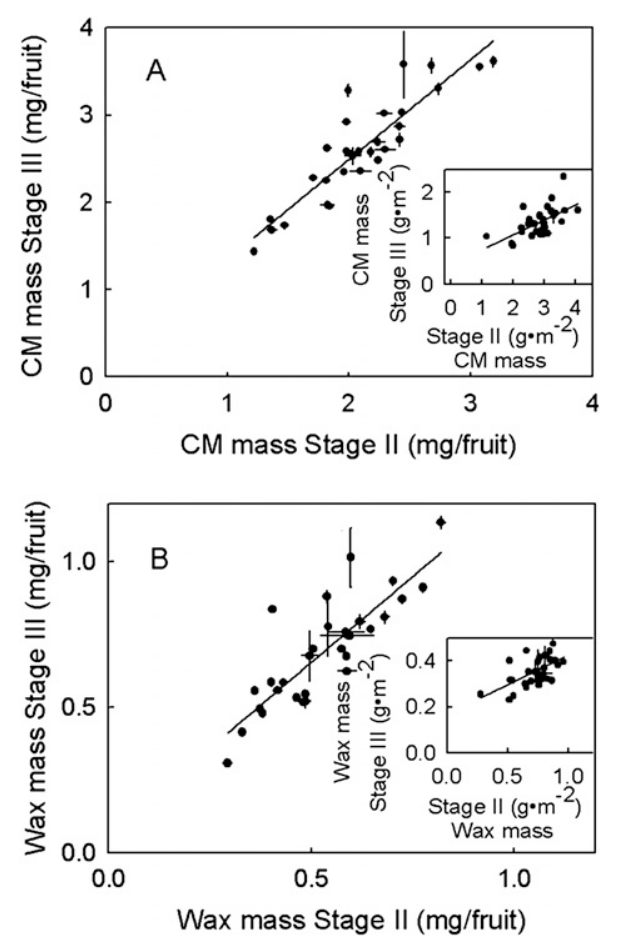

Fig. 2. Relationship between the mass of the cuticular membrane [CM (A)] and of wax (B) per fruit during Stage II and the mature Stage III of 31 sweet cherry cultivars. Data represent means \pm SE of individual cultivars in the 2003 growing season. For regression equations, see Table 3.

$\mathrm{P}_{\mathrm{f}}$ were significantly and positively related $\left[r^{2}=0.771\right.$, $P<0.0001$ (Fig. 3C)]. Both were positively related to stomatal density (Table 6).

\section{Discussion}

Our data established that 1) CM and wax mass, strain of the CM, and stomatal density had high variance components caused by variation among cultivars and hence high heritabilities; 2) there was little CM and wax deposition between Stage II and the mature Stage III in all cultivars investigated; and 
Table 3. Parameter estimates and SE of linear regression equations describing relationships between the mass of the cuticular membrane (CM) and of wax during Stage II and at the fully mature Stage III of 31 selected sweet cherry cultivars.

\begin{tabular}{|c|c|c|c|c|}
\hline \multirow[b]{2}{*}{ Dependent variable } & \multirow[b]{2}{*}{ Unit } & \multicolumn{2}{|c|}{ Parameter estimates } & \multirow[b]{2}{*}{ Coefficient of determination $\left(r^{2}\right)$} \\
\hline & & (slope \pm SE) & (intercept $\pm \mathrm{SE}$ ) & \\
\hline \multirow[t]{2}{*}{$\overline{\mathrm{CM} \text { mass }}$} & $\mathrm{g} \cdot \mathrm{m}^{-2}$ & $0.47 \pm 0.02$ & $-^{z}$ & $0.966^{* * *}$ \\
\hline & $\mathrm{mg} /$ fruit & $1.24 \pm 0.02$ & $-^{z}$ & $0.990 * * *$ \\
\hline & $\mathrm{mg} /$ fruit & $1.30 \pm 0.03$ & $\underline{-}^{\mathrm{z}}$ & $0.980 * * *$ \\
\hline
\end{tabular}

${ }^{\mathrm{z}}$ Y-axis intercept not different from zero at $P<0.05$.

Significance of coefficient of determination at $P<0.001$ indicated by $* * *$.

Table 4. Densities of stomata $\left(d_{\text {sto }}\right)$ of short $\left(d_{\text {short }}\right)$ and long microracks $\left(d_{\text {long }}\right)$ and permeabilities of the sweet cherry exocarp in transpiration $\left(\mathrm{P}_{\mathrm{t}}\right)$ and osmotic water uptake $\left(\mathrm{P}_{\mathrm{f}}\right)$. $^{\mathrm{z}}$

\begin{tabular}{|c|c|c|c|c|c|}
\hline Cultivar & $\begin{array}{l}d_{\text {sto }}[\mathrm{mean} \pm \mathrm{SE} \\
\left.\left(\mathrm{stomata} / \mathrm{mm}^{2}\right)\right]\end{array}$ & $\begin{array}{c}d_{\text {crack short }}[\mathrm{mean} \pm \mathrm{SE} \\
\left.\left(\text { microcracks } / \mathrm{mm}^{2}\right)\right]\end{array}$ & $\begin{array}{c}d_{\text {crack long }}[\mathrm{mean} \pm \mathrm{SE} \\
\left.\left(\text { microcracks } / \mathrm{mm}^{2}\right)\right]\end{array}$ & $\begin{array}{l}\mathrm{P}_{\mathrm{t}}[\mathrm{mean} \pm \mathrm{SE} \\
\left.\left(\times 10^{-9} \mathrm{~m} \cdot \mathrm{s}^{-1}\right)\right] \\
\end{array}$ & $\begin{array}{l}\mathrm{P}_{\mathrm{f}}[\text { mean } \pm \mathrm{SE} \\
\left.\left(\times 10^{-9} \mathrm{~m} \cdot \mathrm{s}^{-1}\right)\right] \\
\end{array}$ \\
\hline Adriana & $0.12 \pm 0.02$ & $3.29 \pm 0.62$ & $0.16 \pm 0.06$ & $2.77 \pm 0.13$ & $28.5 \pm 4.0$ \\
\hline Bianca & $1.29 \pm 0.04$ & $4.40 \pm 1.15$ & $0.60 \pm 0.31$ & $3.82 \pm 0.12$ & $\mathrm{y}^{\mathrm{y}}$ \\
\hline Early Rivers & $1.22 \pm 0.05$ & $0.18 \pm 0.06$ & $0.19 \pm 0.07$ & $3.15 \pm 0.19$ & $37.1 \pm 5.2$ \\
\hline $\mathrm{F} 12 / 1$ & $3.59 \pm 0.20$ & $-^{\mathrm{y}}$ & $-^{\mathrm{y}}$ & $4.24 \pm 0.24$ & $-^{\mathrm{y}}$ \\
\hline Flamingo Srim & $0.35 \pm 0.02$ & $1.98 \pm 0.51$ & $0.12 \pm 0.05$ & $2.11 \pm 0.08$ & $30.7 \pm 7.2$ \\
\hline Hudson & $0.87 \pm 0.03$ & $4.48 \pm 0.93$ & $0.12 \pm 0.05$ & $2.90 \pm 0.12$ & $31.0 \pm 5.9$ \\
\hline Katalin & $1.05 \pm 0.03$ & $6.49 \pm 1.00$ & $1.28 \pm 0.35$ & $3.19 \pm 0.11$ & $69.9 \pm 10.8$ \\
\hline Kordia & $0.70 \pm 0.03$ & $1.63 \pm 0.49$ & $0.63 \pm 0.24$ & $4.35 \pm 0.19$ & $65.1 \pm 16.4$ \\
\hline Margit & $1.34 \pm 0.05$ & $4.22 \pm 0.83$ & $1.64 \pm 0.55$ & $4.47 \pm 0.29$ & $-^{\mathrm{y}}$ \\
\hline Nadino & $0.60 \pm 0.03$ & $7.09 \pm 0.95$ & $4.23 \pm 0.52$ & $6.66 \pm 0.70$ & $134.9 \pm 18.1$ \\
\hline Namare & $1.70 \pm 0.05$ & $0.47 \pm 0.15$ & $0.76 \pm 0.28$ & $4.00 \pm 0.21$ & $83.4 \pm 11.9$ \\
\hline Sam & $1.03 \pm 0.05$ & $0.44 \pm 0.16$ & $0.08 \pm 0.04$ & $2.94 \pm 0.11$ & $31.6 \pm 4.6$ \\
\hline Sunburst & $1.24 \pm 0.05$ & $1.56 \pm 0.41$ & $0.78 \pm 0.38$ & $4.45 \pm 0.20$ & $79.6 \pm 19.3$ \\
\hline Van & $0.81 \pm 0.03$ & $1.12 \pm 0.49$ & $0.51 \pm 0.19$ & $3.93 \pm 0.18$ & $66.9 \pm 12.4$ \\
\hline Grand mean & $1.10 \pm 0.02$ & $2.31 \pm 0.14$ & $0.79 \pm 0.08$ & $3.93 \pm 0.06$ & $67.1 \pm 4.3$ \\
\hline
\end{tabular}

$\overline{{ }^{\mathrm{z}} \text { Microcracks shorter than the longest dimension of the underlying epidermal cell are referred to as short microcracks and those longer as long }}$ microcracks.

${ }^{\mathrm{y}}$ Not determined.

3) the variance components caused by variation among cultivars were low for the density of microcracks and the permeabilities for transpiration and water uptake.

\section{Mass of cuticular membrane and wax, strain, and stomatal density}

$\mathrm{CM}$ and wax mass differed significantly and consistently among cultivars. Across cultivars, CM mass and wax mass were positively related, which is consistent with common biosynthetic pathways for synthesis of fatty acid based precursors of cutin monomers and wax constituents (Peschel et al., 2007; Samuels et al., 2008). The overall deposition pattern of cutin and wax during fruit development was also similar across cultivars. Essentially all CM and wax deposition had occurred by Stage II, when CM and wax mass accounted for $81.0 \% \pm$ $1.4 \%$ and $78.0 \% \pm 1.9 \%$ of their respective masses at maturity. Thus, the increase in surface area between Stage II and the mature Stage III distributed an essentially constant mass of CM over an enlarging surface causing significant elastic and plastic strain (Knoche et al., 2004). The consequences of this mismatch of CM deposition and surface expansion were threefold. First, CM mass per unit area was significantly and negatively related to fruit mass $\left[r^{2}=0.08, P=0.0004\right.$ including fruit of the ' $\mathrm{F} 12 / 1$ ' rootstock; $r^{2}=0.01, P=0.3480$ excluding ' $\mathrm{F} 12 / 1$ ' fruit (Fig. 1A)]. Second, elastic strain of the CM increased as fruit mass increased $\left[r^{2}=0.33, P<0.0001\right.$ and $r^{2}=0.18, P<$ 0.0001 with and without 'F12/1' fruit (Fig. 1C)]. Third, strain of the $\mathrm{CM}$ was negatively related to $\mathrm{CM}$ mass per unit area $\left[r^{2}=0.34, P<0.0001\right.$ and $r^{2}=0.22, P<0.0001$ with and without 'F12/1' fruit (Fig. 1D)].

\section{Density of microcracks, permeabilities in transpiration, and water uptake}

The traits density of microcracks and permeability for transpiration and that for water uptake shared the following common characteristics. For all three traits, the variance component caused by the residual variability was larger than that caused by the variance among cultivars. As a consequence, the heritability of these traits was low (range $H=6.2 \%$ to $30.3 \%$ ). This is not surprising considering the mechanistic basis of 
Table 5. Parameter estimates and SE of multiple linear regression analysis of permeabilities in transpiration $\left(\mathrm{P}_{\mathrm{t}}\right)$ and osmotic water uptake $\left(\mathrm{P}_{\mathrm{f}}\right)$ through exocarp segments excised from the cheek of mature sweet cherry fruit of selected cultivars. ${ }^{\mathrm{z}}$

\begin{tabular}{|c|c|c|c|c|c|c|c|}
\hline Dependent variable & Unit & Independent & Unit & Parameter estimate $( \pm \mathrm{SE})$ & Partial $r^{2}$ & $r^{2}$ & $P$ value \\
\hline \multirow[t]{3}{*}{$\overline{\mathrm{P}_{\mathrm{t}}^{\mathrm{y}}}$} & $\left(\times 10^{-9} \mathrm{~m} \cdot \mathrm{s}^{-1}\right)$ & Constant & & $3.09 \pm 0.25$ & & & $<0.0001$ \\
\hline & & $d_{\text {large crack }}$ & $\left(\right.$ microcracks $\left./ \mathrm{mm}^{2}\right)$ & $0.53 \pm 0.15$ & 0.164 & 0.164 & 0.0009 \\
\hline & & $\mathrm{CM}$ mass & $\left(\mathrm{g} \cdot \mathrm{m}^{-2}\right)$ & $-1.84 \pm 0.79$ & 0.069 & 0.233 & 0.0227 \\
\hline \multirow[t]{3}{*}{$P_{f}^{y}$} & $\left(\times 10^{-9} \mathrm{~m} \cdot \mathrm{s}^{-1}\right)$ & Constant & & $-70.6 \pm 48.7$ & & & 0.160 \\
\hline & & $d_{\text {large crack }}$ & $\left(\right.$ microcracks $\left./ \mathrm{mm}^{2}\right)$ & $28.4 \pm 6.3$ & 0.448 & 0.448 & $<0.0001$ \\
\hline & & $\mathrm{d}_{\text {sto }}$ & (stomata $/ \mathrm{mm}^{2}$ ) & $37.0 \pm 15.7$ & 0.080 & 0.527 & 0.0465 \\
\hline
\end{tabular}

${ }^{\mathrm{z}}$ The independent variables offered were mass of the cuticular membrane $(\mathrm{CM})$ per unit area, the densities of stomata $\left(\mathrm{d}_{\text {sto }}\right)$ of small $\left(\mathrm{d}_{\text {small crack }}\right)$ and large microcracks $\left(\mathrm{d}_{\text {large crack }}\right)$, and the strain of the CM. Microcracks shorter than the longest dimension of the underlying epidermal cell are referred to as short microcracks and those longer as long microcracks. Strain was calculated as the relative decrease in area of the CM disc after excision from the fruit using a cork borer and enzymatic isolation. For details, see text.

${ }^{y_{n}}=64$ and 29 for $P_{t}$ and $P_{f}$, respectively.
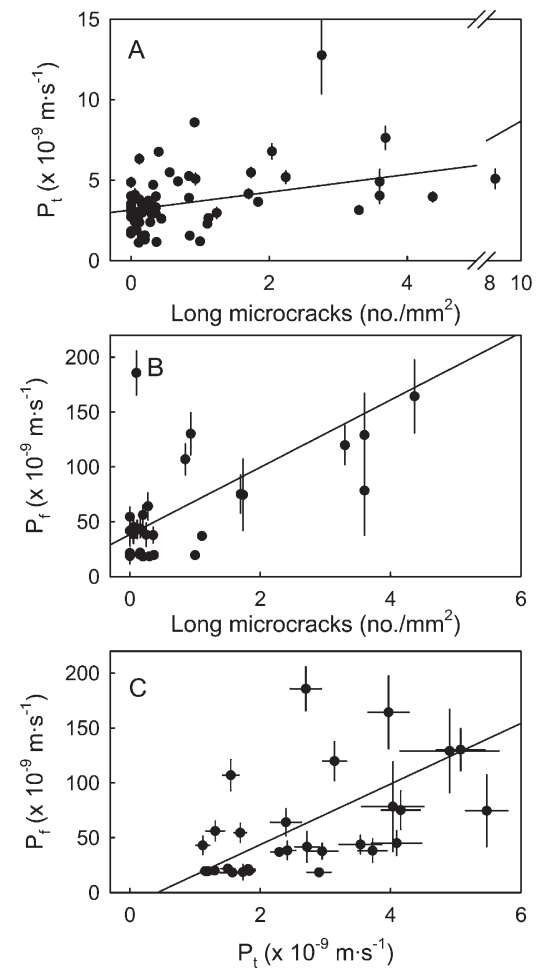

Fig. 3. Relationships between the density of long microcracks and the permeabilities of excised exocarp segments $(\mathrm{ES})$ in transpiration $\left[\mathrm{P}_{\mathrm{t}}(\mathbf{A})\right]$ and osmotic water uptake $\left[\mathrm{P}_{\mathrm{f}}(\mathbf{B})\right]$. Relationships between the $\mathrm{P}_{\mathrm{t}}$ and $\mathrm{P}_{\mathrm{f}}(\mathbf{C})$. ES were excised from the cheek of mature sweet cherry fruit. The number of microcracks was established by fluorescence light microscopy in two size categories. Microcracks longer than the longest dimension of the underlying epidermal cell are referred to as long microcracks and those shorter as short microcracks. Only the former category had a significant effect on $\mathrm{P}_{t}$ and $\mathrm{P}_{\mathrm{f}}$. Individual symbols represents means $\pm \mathrm{SE}$ of 14 to 20 fruit per cultivar and year.

microcracking of the $\mathrm{CM}$ and the role of surface defects including microcracks in water transport. Microcracks result from elastic strain of the CM (Peschel and Knoche, 2005) and from extended exposure of the strained CM to liquid water or high concentrations of water vapor (Knoche and Peschel, 2006). Fruit surface wetness duration is primarily affected by environmental conditions, which are highly variable even among fruit on the same tree. As a result, the residual variability of the density of microcracks is expected to be high. Furthermore, large microcracks were an important determinant of water permeability in transpiration and water uptake.

The observation that $\mathrm{P}_{\mathrm{f}}$ exceeded $\mathrm{P}_{\mathrm{t}}$ by a factor of $24.5 \pm 2.5$ is consistent with earlier observations (Beyer et al., 2005). The higher $\mathrm{P}_{\mathrm{f}}$ is accounted for by viscous flow along polar pathways that in sweet cherry are associated with stomata and microcracks in the CM (Beyer et al., 2005; Weichert and Knoche, 2006). These pathways contributed to osmotic water uptake but to a lesser extent to diffusion, which is the primary mechanism of transport in transpiration (Beyer et al., 2005). This argument is also supported by the significant relationship between the ratio of $\mathrm{P}_{\mathrm{f}} / \mathrm{P}_{\mathrm{t}}$ and the densities of stomata and of large microcracks. Furthermore, the dependence of $\mathrm{P}_{\mathrm{f}}$ on stomatal density that has a high heritability $(H=67.5 \%)$ is likely to account for the higher heritability of $\mathrm{P}_{\mathrm{f}}(H=30.3 \%)$ as compared with $\mathrm{P}_{\mathrm{t}}(H=9.7 \%)$.

\section{Relationships to rain-induced cracking}

From a practical point of view it would be interesting to know to what extent the $\mathrm{CM}$ properties quantified herein account for differences in cracking susceptibility among cultivars. Such analysis is mathematically easy to perform using our data. However, several restrictions and limitations need to be recognized when interpreting the output of such calculations. First, we did not quantify the cracking susceptibility of those batches of fruit used in our experiments. Therefore, we can only relate the means of traits across different years to published data on cracking susceptibility and any information associated with the year-to-year variability of the traits investigated and, possibly, the cracking susceptibility is lost. Second, cracking susceptibility has been quantified using a variety of approaches ranging from cracking indices (CIs) quantified in standardized laboratory assays to rating procedures in the field (Christensen, 1996). Cracking indices are advantageous above rating scores based on field observations, because randomly occurring rain events under orchard conditions are replaced by the standardized immersion assay. To our knowledge, the most comprehensive source of $\mathrm{CI}$ is the compilation published by Christensen (1996). Correlation analysis revealed that these CIs are significantly correlated with rating scores of field cracking susceptibility performed by the federal fruit cultivar office, Wurzen, Germany (W. Pfannenstiel, unpublished data), but the coefficient of correlation was "only" $r=0.62(P=0.0043)$ for 
Table 6. Parameter estimates and SE of linear regression equations for the relationship between permeability $\left(\mathrm{P}, \mathrm{m} \cdot \mathrm{s}^{-1}\right)$ in transpiration $\left(\mathrm{P}_{\mathrm{t}}\right)$ or in osmotic water uptake $\left(\mathrm{P}_{\mathrm{f}}\right)$ and stomata number on excised exocarp segments (sto) of $15\left(\mathrm{P}_{\mathrm{f}}\right)$ to $19\left(\mathrm{P}_{\mathrm{t}}\right)$ sweet cherry cultivars. ${ }^{\mathrm{z}}$

\begin{tabular}{lllccc}
\hline & & & \multicolumn{2}{c}{ Parameter estimates } \\
\cline { 3 - 5 } Dependent variable & \multicolumn{1}{c}{ Yr } & No. & $\begin{array}{c}\text { Slope } \pm \text { SE } \\
\left(\times 10^{-9} \mathrm{~m} \cdot \mathrm{s}^{-1} \text { per stoma }\right)\end{array}$ & $\begin{array}{c}\text { Intercept } \pm \mathrm{SE} \\
\left(\times 10^{-9} \mathrm{~m} \cdot \mathrm{s}^{-1}\right)\end{array}$ & Coefficient of determination $\left(r^{2}\right)^{\mathrm{y}}$ \\
\hline $\mathrm{P}_{\mathrm{t}}$ & 1999 & 248 & $0.029 \pm 0.003$ & $3.15 \pm 0.19$ & $0.220^{* * *}$ \\
$\mathrm{P}_{\mathrm{t}}$ & 2000 & 254 & $0.029 \pm 0.003$ & $2.15 \pm 0.15$ & $0.231^{* * *}$ \\
$\mathrm{P}_{\mathrm{t}}$ & 2001 & 180 & $0.027 \pm 0.004$ & $2.85 \pm 0.25$ & $0.177 * * *$ \\
$\mathrm{P}_{\mathrm{t}}$ & 2003 & 132 & $0.013 \pm 0.003$ & $1.01 \pm 0.16$ & $0.152^{* * *}$ \\
$\mathrm{P}_{\mathrm{t}}$ & 2004 & 104 & $0.002 \pm 0.006$ & $3.15 \pm 0.30$ & $0.001 \mathrm{NS}$ \\
$\mathrm{P}_{\mathrm{t}}$ & Pooled & 918 & $0.020 \pm 0.002$ & $2.65 \pm 0.11$ & $0.095 * * *$ \\
& $1999-2004$ & & & & $0.080^{* * *}$ \\
$\mathrm{P}_{\mathrm{f}}$ & 2003 & 132 & $0.69 \pm 0.21$ & $10.38 \pm 12.44$ & $0.026 \mathrm{NS}$ \\
$\mathrm{P}_{\mathrm{f}}$ & 2004 & 104 & $0.42 \pm 0.26$ & $38.18 \pm 12.71$ & $0.042^{* *}$ \\
$\mathrm{P}_{\mathrm{f}}$ & Pooled & 236 & $0.51 \pm 0.16$ & $26.76 \pm 8.80$ &
\end{tabular}

\footnotetext{
${ }^{\mathrm{z}}$ Analysis was restricted to exocarp segments that remained without microcracks as determined by fluorescence microscopy. For details, see text. y** and *** significant at $P=0.01$ and 0.001 , respectively. NS $=$ nonsignificant.
}

$\mathrm{n}=19$ cultivars (M. Knoche, unpublished data). Third, the CM properties that we focused on in our study relate to water transport across the fruit surface, which is an important but not the only factor in fruit cracking. A second important aspect is the mechanical constitution of the fruit and, in particular, that of the load-bearing structure, the exocarp. There is essentially no published information on this aspect and any factors associated with the mechanical properties of the exocarp are ignored in such multiple regression or correlation analyses. Finally, empirical correlations do not prove functional relationships and hence are of limited value for mechanistic studies. Nevertheless, when performing multiple regression analyses using published CI (Christensen, 1996) and mass of $\mathrm{CM}$, density of stomata, of microcracks, and the data on $\mathrm{P}_{\mathrm{t}}$ as independent variables, the highest $r^{2}\left(r^{2}=0.48, P<0.0001, \mathrm{n}=\right.$ 64) were obtained using stomatal density (partial $r^{2}=0.218$, $P<0.0001$ ) followed by densities of long (partial $r^{2}=0.141$, $P=0.0005$ ) and short microcracks (partial $r^{2}=0.056, P=$ 0.0192 ) and the CM mass per unit area (partial $r^{2}=0.065, P=$ 0.0085 ) as independent variables. Similarly, performing the same analysis, but using $\mathrm{P}_{\mathrm{f}}$ instead of $\mathrm{P}_{\mathrm{t}}$, identified densities of stomata (partial $r^{2}=0.124, P=0.034$ ), of long microcracks (partial $r^{2}=0.096, P=0.047$ ), and the $\mathrm{CM}$ mass per unit area (partial $r^{2}=0.077, P=0.0545$ ) as independent variables that accounted for $52.5 \%\left(r^{2}=0.525, P<0.0003, \mathrm{n}=29\right)$ of the variation of the CI. These analyses demonstrate that maintaining the barrier function of the $\mathrm{CM}$ by 1 ) preventing the formation of microcracks; and 2) maintaining a low stomatal density and a thick CM is helpful in developing less crackingsusceptible cultivars.

\section{Conclusion}

The role of the $\mathrm{CM}$ as a penetration barrier in water uptake requires an intact CM. Based on the data presented here, three strategies for developing less cracking-susceptible fruit may be visualized. First, across the cultivars investigated, a high mass of $\mathrm{CM}$ per unit area equivalent to a thicker $\mathrm{CM}$ was associated with less strain. Also, thicker CMs have more "reserve" for thinning during Stage III development. Selecting fruit for thicker CM is not unrealistic, because the heritability of this trait was fairly high $(H=47.6 \%)$. Second, genotypes may be selected for low strain of the CM. Care must be taken to not simultaneously select for low fruit mass, because strain and fruit mass are positively and significantly related. However, within the large-fruited cultivars (mean mass greater than $10 \mathrm{~g} /$ fruit), strain of the CM still ranged from $75.5 \%$ to $97.0 \%$ indicating significant variability that may be used in breeding efforts. Third, genotypes that deposit significant amounts of cutin and wax also during Stage III would be most interesting, because their CM is likely to be less strained. For example, CMs of sweet cherry leaves or of apple or tomato fruit all have low strain (less than 20\%), most likely because of continuing CM deposition during expansion (Knoche et al., 2011; M. Knoche, unpublished data). Unfortunately, even the comprehensive screening of 31 sweet cherry cultivars did not reveal any significant variation in the CM deposition pattern during Stage III development. Nevertheless, extending the phenotyping beyond the cultivars investigated merits further effort. If genetic variability in this trait was found, it may be used in breeding programs. Finally, our data also demonstrate that selecting for high $\mathrm{P}_{\mathrm{t}}$ or low $\mathrm{P}_{\mathrm{f}}$ is less likely to improve cracking susceptibility. Both properties have a relatively low heritability and a high residual variability possibly because of microcracking of the $\mathrm{CM}$ in response to surface wetness.

\section{Literature Cited}

Beyer, M. and M. Knoche. 2002. Studies on water transport through the sweet cherry fruit surface: V. Conductance for water uptake. J. Amer. Soc. Hort. Sci. 127:325-332.

Beyer, M., S. Lau, and M. Knoche. 2005. Studies on water transport through the sweet cherry fruit surface: IX. Comparing permeability in water uptake and transpiration. Planta 220:474-485.

Christensen, J.V. 1996. Rain-induced cracking of sweet cherries. Its causes and prevention, p. 297-327. In: Webster, A.D. and N.E. Looney (eds.). Cherries. CAB Intl., Wallingford, UK.

Considine, J. and K. Brown. 1981. Physical aspects of fruit growthTheoretical analysis of distribution of surface growth forces in fruit in relation to cracking and splitting. Plant Physiol. 68:371376.

Glenn, G.M. and B.W. Poovaiah. 1989. Cuticular properties and postharvest calcium applications influence cracking of sweet cherries. J. Amer. Soc. Hort. Sci. 114:781-788. 
Knoche, M., M. Beyer, S. Peschel, B. Oparlakov, and M.J. Bukovac. 2004. Changes in strain and deposition of cuticle in developing sweet cherry fruit. Physiol. Plant. 120:667-677.

Knoche, M., B.P. Khanal, and M. Stopar. 2011. Russeting and microcracking of 'Golden Delicious' apple fruit concomitantly decline due to gibberellin A4+7 application. J. Amer. Soc. Hort. Sci. 136:159-164.

Knoche, M. and S. Peschel. 2006. Water on the surface aggravates microscopic cracking of the sweet cherry fruit cuticle. J. Amer. Soc. Hort. Sci. 131:192-200.

Knoche, M., S. Peschel, M. Hinz, and M.J. Bukovac. 2000. Studies on water transport through the sweet cherry fruit surface: Characterizing conductance of the cuticular membrane using pericarp segments. Planta 212:127-135.

Martin, J.T. and B.E. Juniper. 1970. The cuticle of plants. Edward Arnolds, London, UK.

Nobel, P.S. 1999. Physicochemical and environmental plant physiology. Academic Press, New York, NY.
Orgell, W.H. 1955. The isolation of plant cuticle with pectic enzymes. Plant Physiol. 30:78-80.

Peschel, S., M. Beyer, and M. Knoche. 2003. Surface characteristics of sweet cherry fruit: Stomata number, distribution, functionality and surface wetting. Sci. Hort. 97:265-278.

Peschel, S., R. Franke, L. Schreiber, and M. Knoche. 2007. Composition of the cuticle of developing sweet cherry fruit. Phytochemistry 68:1017-1025.

Peschel, S. and M. Knoche. 2005. Characterization of microcracks in the cuticle of developing sweet cherry fruit. J. Amer. Soc. Hort. Sci. 130:487-495.

Samuels, L., L. Kunst, and R. Jetter. 2008. Sealing plant surfaces: Cuticular wax formation by epidermal cells. Annu. Rev. Plant Biol. 59:683-707.

Weichert, H. and M. Knoche. 2006. Studies on water transport through the sweet cherry fruit surface: 10 . Evidence for polar pathways across the exocarp. J. Agr. Food Chem. 54:3951-3958. 